\title{
GENEALOGIA FEMININA: DIÁLOGO SILENCIOSO ENTRE GERAÇÕES
}

\author{
Flávia Obino Corrêa Werle \\ Universidade do Vale do Rio dos Sinos, Brasil.
}

Resumo

Este artigo, desenvolvido na linha da História Cultural, adota como metodologia uma abordagem biográfico-narrativa. Discute, dentre outros conceitos, os de tradição, inovação, genealogia feminina na perspectiva de novos enfoques para a História da Educação. Considera a memória, tanto como um discurso, quanto como uma presença nos objetos e cultura material. Analisa um objeto guardado e presenteado de gerações em gerações a ser usado pelas mulheres de uma mesma família na hora do parto. Problematiza o tema da formação humana em espaços de relações familiares e em modalidades não escolarizadas e questiona o que as irmãs ensinam umas às outras, que aprendizagens ocorrem nas relações entre mulheres que são vizinhas, amigas, primas, tias, sobrinhas.

Palavras-chave: história da educação, tradição, memória.

\section{FEMALE GENEALOGY: \\ SILENT DIALOGUE BETWEEN GENERATIONS}

Abstract

The methodology of this article, developed along the lines of Cultural History, is a biographicalnarrative approach. Among other concepts, it discusses tradition, innovation, female genealogy from the perspective of new ways to focus on History of Education. It considers memory both as a discourse and as a presence in objects and material culture. An object stored and gifted from generation to generation, to be used by the women of a same family at the time of childbirth is analyzed. It problematizes the topic of human formation in spaces of family relations and in nonschooled modes, and asks what the sisters teach each other, what learnings occur in the relationships between women who are neighbors, friends, cousins, sisters, nieces.

Key-words: history of education, tradition, memory. 


\section{GENEALOGIA FEMENINA: \\ DIALOGO SILENCIOSO ENTRE GENERACIONES}

Resumen

Este artículo, desarrollado en el contexto de la Historia Cultural, adopta como metodología una temática biográfica-narrativa. Trata los conceptos de tradición, inovación, genealogía femenina desde la perspectiva de nuevos enfoques para la Historia de la Educación. Considera a la memoria, tanto como un recurso, así como una presencia en los objetos y en la cultura material. Analiza un objeto guardado y transmitido de generaciones en generaciones, para ser usado por las mujeres de una misma familia a la hora del parto. Discute sobre el tema de la formación humana en espacios de relaciones familiares en modalidades no escolarizadas y cuestiona lo que las hermanas se enseñan unas a otras, que aprendizajes surgen en las relaciones entre mujeres que son vecinas, amigas, primas, tías, sobrinas, hijas, madres, abuelas.

Palabras-clave: historia de la educación, tradición, memoria.

\section{GÉNÉALOGIE FEMININ: DIALOGUE ENTRE LES GENERATIONS}

\section{Résumé}

La méthodologie de cet article, développé le long des lignes de l'histoire culturelle, une approche biographique narrative. Parmi les autres concepts, il aborde la tradition, l'innovation, la généalogie féminine dans la perspective de nouvelles façons de se concentrer sur l'histoire de l'éducation. II considère la mémoire à la fois comme un discours et une présence dans les objets et la culture matérielle. Analisé un objet stocké et doué de génération en génération, pour être utilisé par les femmes d'une même famille au moment de l'accouchement. II problématise tle sujet de la formation humaine dans des espaces de relations familiales et dans les modes non-scolarisés, et demande à ce que les sœurs enseignent l'autre, ce qui se produit apprentissages dans les relations entre les femmes qui sont des voisins, des amis, cousins, cousines, sœurs, nièces. Mots-clé: histoire de l'éducation, de la tradition, la mémoire. 
ste texto ${ }^{1}$ vincula-se a uma perspectiva de história cultural e social, focando uma temática situada às margens dos grandes debates da sociedade atual, na intersecção entre genealogias femininas, biografização, tradição, inovação e História da Educação. Toma como empiria um objeto material, qual seja, o Breve que protege na hora do parto, presente no cotidiano de mulheres de uma família, no início do século 20 e que é ressignificado aqui, no contexto da segunda década do século 21 . A ressignificação dá a ver, também, minha posição de professora universitária vinculada ao campo da História da Educação e a possibilidade de problematização de novos temas para este campo. É um texto que trata de uma particularidade do mundo feminino relacionada à idade, saúde, beleza e maternidade.

\section{Discussões acerca do conceito de tradição e inovação}

Para discutir tradição e inovação apóio-me em alguns autores de diversos campos do conhecimento, como Antropologia, História, Sociologia, Filosofia:

A palavra tradição vem do latim: traditio. O verbo é tradire, e significa precipuamente entregar, designa o ato de passar algo para outra pessoa, ou de passar de uma geração a outra geração. Em segundo lugar, os dicionaristas referem a relação do verbo tradire com o conhecimento oral e escrito. Isso quer dizer que através da tradição, algo é dito e o dito é entregue de geração a geração. De certa maneira, estamos, pois, instalados numa tradição, como que inseridos nela, a ponto de revelar-se muito difícil desembaraçar-se as suas peias. Assim, através do elemento dito ou escrito algo é entregue, passa de geração, e isso constitui a tradição - e nos constitui. (Bornheim, 1997, p. 18)

No trecho de Bornheim (1987) está evidente o sentido de tradição como estabilidade, como transmissão de algo de uma pessoa para outra, de um grupo geracional para outro, de vínculo entre passado e presente. Trata-se do conceito tradicional de tradição que envolve transmissão de uma mensagem sem mudanças.

Expandindo esta abordagem Bornheim (1987) destaca noções de previsão e segurança, que acompanham a concepção de tradição:

A vontade da tradição está em querer-se tradição, e ela se quer tão totalmente tradição que se pretende eterna, determinando não apenas o passado e o presente, mas o próprio futuro, portanto tudo pode ser previsto, exige-se a antecipação: tudo vai ser sempre fundamentalmente idêntico, sem percalços com o possível surto da alteridade. A tradição se pretende, assim, uma grande segurança - nós estamos na própria segurança, vivemos numa resposta e estamos assegurados nela, ela é nosso principio. (Bornheim, 1997, p. 18)

Segurança, previsibilidade, pré-determinação são noções que acompanham a idéia de tradição, a qual envolve, também, valores que constituem uma sociedade, valores que pautam significativamente o comportamento humano.

${ }^{1}$ Este artigo foi escrito originalmente para a participação no painel Invenções e tradição na História da Educação do qual fizeram parte Marta Maria Chagas de Carvalho (USP) e Maria del Mar del Pozo Andrés (UAH/Espanha), incluído no $6^{\circ}$ Congresso Brasileiro de História da Educação, realizado na Universidade Federal do Espírito Santo, Brasil, dias 16 a 19 de maio de 2011. Foram introduzidas modificações substanciais em relação à versão original. 
Nesta dimensão tradicional de tradição está envolvida a questão da autenticidade e o quanto uma tradição conforma indivíduos e grupos mediante práticas fixas e repetidas.

São fortes as afirmativas de Bornheim (1987) de que a tradição nos constitui, que somos organizados pela tradição, de que ela é o nosso princípio e que estamos assegurados nela. Soa como se fossemos, absoluta e irremediavelmente, passivos e tomados pelas tradições. Deste ponto de vista pode-se chegar a um esgotamento do tema na História e na História da Educação.

Há, entretanto, autores que propõem uma compreensão de tradição menos restritiva, envolvendo repetição, mas também alterações, modificações. Hobsbawn (1997) ao cunhar o termo tradição inventada articula as dimensões reiterativa e de modificação, que poderiam inicialmente ser consideradas opostas e não contidas na tradição:

Por tradição inventada entende-se um conjunto de práticas normalmente reguladas por regras tácita ou abertamente aceitas; tais práticas de natureza ritual ou simbólica visam inculcar certos valores e normas de comportamento através da repetição, o que implica, automaticamente, uma continuidade em relação ao passado [...] Em poucas palavras, elas são reações a situações novas que ou assumem a forma de referência a situações anteriores, ou estabelecem seu próprio passado através da repetição quase que obrigatória. (Hobsbawn, 1997, p. 9)

A invenção das tradições expressa, pois, a compreensão de que estruturas estáveis, quase imutáveis, que ordenam aspectos da vida, são tensionadas em contraste com mudanças e novos contextos. Continua Hobsbawn (1997, p. 10), "o objetivo e a característica das tradições, inclusive as inventadas é a invariabilidade. O passado real ou forjado a que elas se referem impõe práticas fixas (normalmente formalizadas), tais como a repetição."

Certa dinamicidade perpassa o conceito de invenção da tradição ao considerar a impossibilidade de separar tradição e inovação. Tradição inventada é uma idéia ampla que admite, se é que poderíamos dizer, gradações em termos de sua institucionalização e permanência no tempo: “Inclui tanto 'tradições' realmente inventadas, construídas, formalmente institucionalizadas, quanto as que surgiram de maneira mais difícil de localizar num período limitado e determinado de tempo" (Hobsbawn, 1997, p. 9).

A idéia de tradições inventadas sugere vários elementos associados. Considera os poderes dos grupos ou indivíduos que as instauram - político, simbólico, econômico -, os grupos que as instituem e os que as mantém - elites ou grupos subalternos, mulheres, grupos de excluídos -, as formas de comunicação e de disseminação, o conjunto de recursos nisso envolvidos. Viñao (2002) utiliza o termo difusão como sinônimo de aplicação de uma inovação em vários contextos, ponderando que toda a difusão supõe modificação ou adaptação. Acentua que o movimento de renovação, de inovação não é homogêneo e que é impossível evitar conflitos, desvios e dissidências dentro de um movimento inovador.

Tradições inventadas podem associar-se a processos de institucionalização, a existência de práticas presentes em âmbito local e global e de normas assemelhadas que ocorreram ou estejam ocorrendo em outros lugares. A respeito das ambigüidades entre o local e o global, entre culturas com tradições mais ou menos fortes, Burke (2003) refere a homogeneização cultural e crioulização do mundo. Diz o autor que é preciso ter variadas 
formas de expor as relações entre culturas "precisamos de vários [termos] para fazer justiça tanto ao agente humano (como no caso da apropriação ou da tradução cultural) quanto às modificações das quais os agentes não têm consciência (como no caso da hibridização e da crioulização)" (Burke, 2003, p. 63). A idéia de homogeneização cultural considera que no nível global vemos uma redução da diversidade, embora, "no nível do individuo há mais escolhas, mais liberdade, uma ampliação de opções” (Ibid., p. 109). Acrescenta ainda o autor a respeito de crioulização do mundo.

estamos vendo a emergência de uma nova forma de ordem cultural, uma ordem cultural global, mas que [...] pode rapidamente se diversificar, se adaptando a diferentes ambientes locais. Em outras palavras, as formas híbridas de hoje não são necessariamente um estágio no caminho para a cultura global homogênea. (Ibid., p. 115)

O que Burke (2003) designa de crioulização decorre de processos de diversificação e adaptação, o que se aproxima da idéia de difusão da inovação em vários contextos tratada por Viñao (2002), a qual é também renovação, adaptação, que ocorrem mediante embates, desvios, infidelidades.

As tradições são, entretanto, uma referência, um substrato para as inovações. Viñao (2002), ao se referir ao movimento de renovação pedagógica na Espanha da década de 1960, destaca a importância das tradições como referência, como ponto de apoio para a inovação. Para ele, as debilidades de tais movimentos decorreram da ausência de uma tradição nas quais as práticas de renovação pudessem se apoiar ou que pudessem servir de referência. $\mathrm{Na}$ ausência de referencias próprias, a busca foi feita junto a práticas de outros países. Esta busca externa de práticas de renovação não está, entretanto, isenta de adaptações, inovações, o que afasta a possibilidade de uma ordem cultural global, como diz Burke (2003). Viñao (2002) e Burke (2003) não utilizam uma mesma terminologia, mas debatem um conjunto de idéias aproximadas.

Concluo, portanto, que associar invenção à tradição sugere, inversamente, que a invenção está contaminada de tradição, de repetição e de continuísmo, de forma que não apenas a tradição é que vai sendo alterada por traços de invenção. A invenção se consolida, recebe adesões, se institucionaliza e vai se tradicionalizando, tornando-se comum, usual, estabelecendo seguranças pela repetição e pretendendo se eternificar como a tradição mais tradicional.

Peter Burke por tanto, auxilia na compreensão das dimensões menos restritivas de tradição. Ele nos provoca ao indagar: "quando, em quais circunstâncias, uma tradição deixa de ser uma tradição?" (2007, p. 17). Nesta pergunta está a perspectiva de que uma tradição não permanece sempre igual, ela se transforma, se modifica, se adapta. Ela assume traços de atualidade ou ela vai esmaecendo, sendo paulatinamente abandonada, não mais se transmitindo de geração em geração ou transmitindo-se com alterações, restritamente. Peter Burke (2003) reitera a noção de invenção da tradição de Hobsbawn, ao afirmar que toda a "inovação é uma espécie de adaptação" (p. 17). É nesta direção que anteriormente afirmei que a invenção está contaminada de tradição e que a invenção pode se tradicionalizar pela institucionalização e repetição.

Ora, se não existe uma fronteira cultural nítida e firme entre grupos, também não há fronteiras entre as diferentes tradições destes grupos: "Às vezes, a inovação aparente 
esconde a persistência da tradição; outras vezes, a continuidade aparente disfarça inovações" (Burke, 2007, p. 20).

O autor, portanto, ao discutir os processos de hibridação e cultura contribui para ampliar este debate. Cultura inclui atitudes, mentalidades, valores e suas expressões, concretizações ou simbolizações em artefatos, práticas e representações; diz que "todas as culturas estão envolvidas entre si" e não há cultura única ou pura, todas são hibridas, heterogêneas. Para ele,

o preço da hibridação, especialmente naquela forma inusitadamente rápida que é característica de nossa época, inclui a perda de tradições regionais e de raízes locais. Certamente não é por acidente que a atual era da globalização cultural, [...] é também a era das reações nacionalistas ou étnicas. (Burke, 2003, p. 20)

O autor ressalta a tensão entre tradição e hibridismo a ponto de indagar: "Podemos falar de uma tradição híbrida?" (Burke, 2007, p. 18), "uma vez que encontramos hibridização quase que em toda parte na história?” (Burke, 2003, p. 20). O hibridismo cultural ocorre em diferentes domínios da vida humana: nas festividades, nos estilos de música, na arquitetura, na literatura, nas práticas alimentares, e, logicamente, nas tradições:

Em outras palavras, todas as tradições culturais hoje estão em contato mais ou menos direto com tradições alternativas... Por conseguinte, as tradições são como áreas de construção, sempre sendo construídas e reconstruídas, quer os indivíduos e os grupos que fazem parte destas tradições se dêem ou não conta disto. (Burke, 2003, p. 102)

Pode-se dizer que a perspectiva de autenticidade e permanência das tradições é impensável pela criatividade da recepção e a re-negociação de significados que cada indivíduo e grupo, em seu tempo e espaço sócio-histórico, vão articulando. A tradição na perspectiva da recepção leva em consideração, segundo Burke (2007), um processo duplo de descontextualização e recontextualização, de adaptação. Adaptação consiste no empréstimo de partes de uma cultura para incorporá-las numa estrutura tradicional, o que também é chamado de bricolagem, ou de apropriação ou reutilização.

Quais as aproximações entre Hobsbawn (1997) e Burke (2007) na abordagem do tema da tradição?

Burke (2007), ao chamar a atenção para a descontextualização e adaptação, acentua o receptor e seu papel ativo e Hobsbawn (1997), ao referir a tradição inventada, problematiza mais a perspectiva "sempre foi e sempre será assim" (p. 10), as origens da tradição.

Grande parte das discussões de Burke (2007) convergem com as de Hobsbawn (1997). A adaptação, por vezes, surge para conservar velhas práticas em condições novas ou usar modelos antigos para novos fins, entretanto, "a inovação não se torna menos nova por ser capaz de revestir-se facilmente de um caráter de antiguidade" (Hobsbawn, 1997, p. 13).

A tradição inventada, cunhada por Hobsbawn, contempla a mudança e a repetição. Burke (2007) não se refere à tradição inventada, mas de tradição híbrida, destacando as interfaces com tradições alternativas e a importância da recepção e dos movimentos de descontextualização e recontextualização de velhas e consolidadas tradições. 


\section{Tradição e inovação em estudos de história da educação}

No campo da História da Educação Viñao (2002) contribui ao discutir mudança, reformas, inovações e cultura escolar.

No livro Sistemas educativos, culturas escolares e reformas, Viñao (2002) discute a relação entre cultura escolar e inovação. A inovação educativa, como a mudança na escola, constitui uma aventura que, aparentemente, não se articula e até se "opõe à idéia ou mesmo À existência de uma cultura escolar, de um conjunto de tradições e práticas com uma certa continuidade e permanência ao longo do tempo" (Viñao, 2002, p. 111). Tal oposição entre inovação e cultura escolar, já que esta se caracteriza por permanência e continuidade, não é tão real, pois a inovação se situa frente à culturas estabelecidas, ou seja, se inova e renova conforme o contexto e as circunstâncias. Ademais, "a inovação e a mudança criam sua própria cultura, suas continuidades, persistências e tradições" (Viñao, 2002, p. 111). Isto significa que "a inovação se move entre a necessidade de estabelecer continuidades e a também necessidade de pôr sempre em questão tanto a teoria como a prática" (Viñao, 2002, p. 112).

Viñao (2002) refere o dilema entre continuidade e mudança - "a continuidade acaba com a inovação e a mudança com sua consolidação" (p. 112). Destaca a necessidade de considerar a relação entre difusão da inovação e os processos de adaptação: "a difusão ou aplicação de uma inovação em um contexto diferente daquele em que se originou - e por outros professores e alunos - implica sempre sua interpretação e adaptação" (2002, p. 112). Portanto, Viñao traz para o âmbito da História da Educação o debate entre tradição e inovação pela análise de cultura escolar versus inovação e mudança. Os processos de adaptação não operam, necessariamente, em contraposição à propostas inovadoras:

o êxito ou fracasso de toda a reforma, mudança ou inovação depende, em primeiro lugar, de que possa ser interpretada, acomodada ou adaptada ao contexto, e, segundo, de como o seja, já que em dito processo cabem desde a adaptação criativa e inteligente, até o ritualismo, o simples rechaço ou a tergiversação que desvirtua os propósitos iniciais. (Viñao, 2002, p. 119)

Entendo que Viñao (2002) discute, de alguma forma, os processos de apropriação ao referir às reformas educacionais. Este autor não pronuncia formalmente apropriação, mas a afirmativa de que a difusão da inovação implica sempre em interpretação e adaptação e o destaque que faz aos conflitos, dissidências e a movimentos de acomodação sugerem que, de seu ponto de vista, é preciso considerar micro movimentos interpretativos e de insubordinação mesmo no âmbito de inovações educacionais.

A visão tradicional de tradição poderia simplesmente registrar: "a educação não muda porque os professores ensinam como a eles se lhes foi ensinado, ou por sua mentalidade conservadora, tradicional, rotineira, acomodada e, inclusive, recalcitrantemente oposta às mudanças" (Viñao, 2002, p. 117), ou descrever a inércia gerada por certa burocracia acentuando que "as instituições e sistemas educativos geram, com o passar do tempo e por sua própria dinâmica e forças internas, algumas culturas escolares - ao modo de sedimentos institucionais - e alguns traços ou tendências que, em maior ou menor grau, se impõem aos protagonistas ou atores da educação" (Viñao, 2002, p. 118). Entretanto, esta concepção tradicional que inspira estas descrições não considera a capacidade de infidelidade normativa (Lima, 2001), as estratégias de autonomia de 
grupos e indivíduos, o movimento gerado pelo exercício de poderes locais, as rearticulações regionais, a capacidade de apropriação, diálogo e negociação dos atores.

A consideração do tema tradição conduz do conceito tradicional de tradição aos de tradição inventada, tradição híbrida, tradições como áreas em construção, recepção da tradição, adaptação, descontextualização e recontextualização da tradição. A discussão de tradição avança no cotejo com a idéia de inovação, cuja existência erige-se por sobre uma referência prévia, algo existente, uma tradição e, por outro lado, a inovação cria sua própria tradição.

Este conjunto de conceitos inspiram e têm ressonância na construção de objetos de estudo em História e em História da Educação. Estas se apresentam tencionadas por novos temas, novas abordagens e procedimentos metodológicos.

Peter Burke (1992), na intenção de descrever a Nova História, apresenta-a, resumidamente, em seis pontos, indicando o que ela é em contraste com o paradigma tradicional de história: 1) tradicionalmente a História diz respeito à Política, relacionada ao Estado, enfatizando a perspectiva nacional e internacional; a Nova História se interessa por toda a atividade humana. 2) Os historiadores tradicionais pensam na História como essencialmente uma narrativa dos acontecimentos e a Nova História trabalha com temas marginais e considera as subjetividades. 3) A história tradicional oferece uma visão de cima: grandes homens, grandes generais, grandes estadistas; os grandes livros. A Nova História busca refletir acerca da História vista debaixo. 4) No paradigma tradicional, a História deveria ser baseada em "documentos, registros oficiais, preservados em arquivos, os quais, em geral, expressam o ponto de vista oficial” (Burke, 1992, p. 13). 5) O paradigma tradicional propõe um tipo de pergunta que endereça mais para o acontecimento e para ações individuais. A Nova História questiona processos, busca dissidências, adaptações, movimentos de grupos sociais subalternos. 6) Ademais, o paradigma tradicional considera que a História é objetiva, pretende informar os fatos como eles realmente aconteceram, mas a Nova História considera vozes variadas, para o que a História Oral contribui sobremaneira.

Os pontos pelos quais Burke (1992) resume o impacto da Nova História no paradigma tradicional de História contribuem para a reflexão acerca da História da Educação, a ampliação de seu campo e as perspectivas de compreender a tradição e a inovação. Novos objetos trazem exigências metodológicas novas, provocam a revisitação ou busca de novas fontes - diários, livros de memórias, cadernos, impressos, livros didáticos, materiais de leitura popular, materiais pessoais. Novos objetos pedem apoio teórico-conceitual diferenciado - gênero, etnia - e conduzem à aproximações com outros campos do conhecimento - sociologia, antropologia, psicologia. Novos objetos inspiram diferentes abordagens metodológicas e o afastamento da perspectiva meramente narrativa de acontecimentos e de políticas de Estado de longo prazo e abordagens macro. História das disciplinas escolares, história da infância, são exemplos de novas abordagens, assim como o estudo de formas de Educação que se realizam além dos espaços institucionalizados dos sistemas de ensino, fora das escolas e salas de aula.

Analisar historicamente as mudanças em educação envolve enfrentar questões difíceis de equacionar. Exigi que o pesquisador focalize outros elementos que não apenas as regularidades, que aborde temas que permanecem na sombra. Novo enfoque de História da Educação levaria a apontar descontinuidades na explicação histórica bem 
como a indagar sobre outras culturas - das funcionárias, merendeiras, das gestoras, assim como dos professores, dos alunos, das famílias.

O novo enfoque em História da Educação pode fazer-nos olhar para as culturas tradicionais especificas das diferentes escolas, de cada nível acadêmico, de cada grupo de atores e atentar para as gerações de atores que compõem a instituição. Um novo enfoque propiciaria discutir estratégias não caracterizadas dentro da pedagogia tradicional, mas que implicam em formação, experiências educativas mais horizontais, solidárias e coletivas entre vizinhança, colegas e familiares, por exemplo.

Viñao (2002) aponta para a necessidade de proceder a análises históricocomparativas sobre os processos de inovação nos sistemas educativos, considerando também culturas e sub-culturas escolares frente a reformas:

Escasseiam [...] os estudos sobre as condições que facilitam ou entorpecem a aparição destes processos, as pessoas que os iniciam ou promovem, as instituições, lugares e contextos que constituem o foco de irradiação dos mesmos, e seus modos de difusão, estancamento, transformação e desaparecimento. (Viñao, 2002, p. 115)

O autor propõe perguntas instigadoras. As inovações identificadas pelos historiadores ocorreram em que níveis dos sistemas educativos? A prevalência de estudos acerca deste ou daquele nível de ensino se constituiu devido a preferências dos pesquisadores, ou pelas características peculiares destes níveis de ensino ou por ambos os aspectos? Afirma ele que

necessitamos mais estudos sobre processos concretos de reforma e inovação, realizados desde uma perspectiva comparada, que nos ilustrem tanto sobre sua origem, difusão e evolução, como sobre as relações existentes entre si e entre ambas e as mudanças sociais, políticas e tecnológicas. (Viñao, 2002, p. 117)

Viñao (2002) instiga, portanto, para uma História da Educação que descortine os movimentos inovadores, as resignificações de práticas tradicionais, os processos de apropriação que recontextualizam as tradições.

\section{O Breve: tradição, inovação, apropriação e recontextualização de um objeto feminino}

O trecho que segue é uma contribuição no sentido de dar a ver formas de sociabilidade e formação entre mulheres, pela consideração de um pequeno objeto confeccionado em tecido e papel, a partir do qual se interpreta a relação avó-mãe-filha num momento especial que não ocorre em simultâneo a todas elas, pois que são de gerações diferentes, mas para cada uma em tempos históricos específicos: a gravidez e o parto. Constitui um tipo de narrativa genealógica que trata de mulheres de uma mesma família e manifesta de alguma forma, as necessidades de espelhamento e proximidade, por um lado, e de diferenciação e distanciamento, por outro, entre avós, mães e filhas. A discussão acerca das genealogias femininas traz, silenciosamente imbricadas, as idéias de tradição, inovação, recepção de tradições, descontextualização e recontextualização de tradições frente a contextos que são diferenciados para cada mulher e cada geração. 
A importância das genealogias femininas é destacada por Luce Irigaray (2002, p. 1): "é afirmando a diferença, que a mulher pode libertar-se da dominação sobre ela da cultura do masculino. Para cultivar esta diferença, deve definir as mediações próprias de seu gênero: em nível de linguagem, do direito, da religião, da genealogia". Para ela é preciso "tirar do esquecimento as genealogias femininas" não para encobrir a figura do pai mas para fortalecer a "identidade do dois" (Irigaray, 2002, p. 6).

Para Almeida (2004, p. 2),

são genealógicos os textos que narram as relações das protagonistas femininas com seus pares familiares sejam elas mães, avós, tias, filhas, netas, bisavós, irmãs, madrinhas, etc. Textos que narram as relações das mulheres com outras mulheres que não fazem parte de sua ascendência ou descendência familiar direta; mulheres que são determinantes em suas vidas e biografias, sejam elas alunas, professoras, vizinhas, babás, nanas, empregadas, amigas, terapeutas, etc. E são genealógicos os textos que tratam das protagonistas, leitoras ou autoras, que dialogam com autoras e leitoras de outras épocas, num procedimento que tem como objetivo estabelecer uma linhagem, a possibilidade de uma ancestralidade literária.

Esta mesma autora (Almeida, 2003), ao analisar genealogias femininas no campo da literatura, apóia-se em autores que referem a relação entre mãe e filha como "agridoce" pela tensão permanente entre parecer e diferenciar-se, ou como uma "ligação por fusão", de características ambivalentes. A autora indaga: "o que poderiam herdar as mulheres de outras mulheres - avós, mães, filhas, bisavós, tias, madrinhas - quando elas não são senhoras sequer de seus próprios nomes, destinos, menos ainda de suas vontades ou de um patrimônio?" (Almeida, 2003, p. 22) Nesta parte do texto analiso um tipo de herança entre as mulheres de minha família, um objeto que acompanha na hora do parto. Não uma herança de valor econômico, importante no mercado. É uma herança de pertencimento, compartilhamento, ascendência, parecença, de espaços de mulheres.

Este texto, portanto, é genealógico no primeiro sentido apresentado por Almeida (2003). A narrativa que estabeleço prende-se a minhas lembranças relacionadas a um ato de minha mãe e informações oferecidas por ela, reflexões estabelecidas no contexto de minha família e no diálogo com lembranças das demais mulheres que constituem minha constelação familiar. É também biográfico na medida em que eu, como autora deste texto, contextualizo a mim, narro minha visão e construo significados acerca deste objeto de memória. Como diz Suárez (2009, p. 17), "toda narração ou testemunho autobiográfico ya suponen em si mismos interpretación, construcción y recreación de sentidos, lecturas do próprio mundo y de la própria vida".

Sim, este artigo está transpassado por minhas visões. Como dizem Weiduschadt e Fischer $(2009$, p. 7) "a lembrança depende dos significados que o depoente concede às suas reminiscências, ele vai evidenciar o que mais Ihe dá sentido". Por outro lado, esta parte do artigo é um resgate de memórias, minhas e de outros familiares - pessoas e objetos -, pois "a memória além de ser um produto do discurso, também está presente nos objetos, nos artefatos, a cultura material, sendo possível recordar fazendo relações com objetos produzidos e preservados pelos grupos" (Weiduschadt; Fischer, 2009, p. 79)

Por um lado, este trecho constrói uma reflexão na linha da genealogia feminina relacionada ao parto, situação que mulheres partilham entre si, mas que, em sua condição de avós, mães e filhas, não a vivem conjuntamente, mas em tempos de 
existência diferenciados. Tempos de existência que são também históricos e diferenciados em termos de condições familiares, sócio-culturais, políticas e de apoios de saúde. Por outro é, também, uma escrita auto-biográfica singular, redigida por mim, a autora deste artigo, uma mulher e que ao fazer esta narrativa-interpretativa demonstra sua identidade feminina, sua situação profissional e ensaia uma construção de sentidos com relação ao Breve no diálogo com o que supõe foram práticas de outras mulheres de sua família - sua avó e sua mãe. Nele se expressam processos de construção de mim mesma pelo registro de sentimentos, contextualização espaço-temporal e relacional os quais são também processos de singularização e de apropriação frente a práticas vigentes no seio do espaço social familiar e, especialmente, frente a minha avó, tia-avó e mãe. Como diz Halbwachs (1990, p. 51) "cada memória individual é um ponto de vista sobre a memória coletiva, que este ponto de vista muda conforme o lugar que ali eu ocupo e que este lugar mesmo muda segundo as relações que mantenho com outros meios".

Em termos de genealogia feminina este texto representa um esforço de memória individual que se assenta em um objeto guardado por mulheres como monumento, confeccionado por uma mulher, minha tia-avó, e valorizado por várias gerações de mulheres - minha avó e mãe, quem sabe as tias - que o conservaram como prática, recordação e lembrança. Este texto tem traços da metodologia história de vida, embora não tenham sido utilizados gravadores e nem realizadas transcrições de entrevistas. As informações obtidas junto a minha mãe ocorreram em forma de conversa - as conversas cotidianas são, muitas vezes, modalidades de construção de si, de identidade e de formação -, como reminiscências e recordações do passado. Sabe-se que "a memória tem a ver com o tempo vivido, por isso, sujeitos que participaram de um processo educativo inventam e reinventam suas recordações" (Weiduschadt; Fischer, 2009, p. 75). Embora as autoras citadas falem de processos educativos escolares, neste texto, evidencia-se um processo formativo informal, na linha de uma tradição familiar que se apresenta a ser seguida e, portanto, com impacto formativo, inventado e reinventado por diferentes gerações.

Preliminarmente busco o significado da palavra Breve, para então apresentar o objeto de mulheres e como ele chegou a este circuito de pesquisa.

O sentido de um Breve parece ser variado, indicando tanto superstição, feitiços como orações e religiosidade. O Guia das religiões populares do Brasil (Gaspar, 2002) caracteriza Breve como algo artesanal. São saquinhos de pano com diversos usos e feitiços que envolvem e protegem objetos mágicos, orações e elementos para feitiço. $O$ Breve para a saúde é uma trouxinha com sal ou ervas - o sal reforça a duração de todos os feitiços. O Breve de proteção é também um saquinho de pano, de feitio triangular ou quadrado, contendo carvão, alho, conchas, búzios, dentes - de javali, de leite -, moedas, pedras, ervas, madeiras, ferro, fitas ou fios. O Breve de amor costuma ser feito em feitio de coração, com pano vermelho ou rosa e o conteúdo pode consistir em ervas apropriadas, pedras, moedas, conchas, orações.

$\mathrm{Na}$ tradição católica popular encontram-se pequenas rezas e pedidos escritos em papel deixados nos altares das igrejas ou frente a imagens de santos de devoção. Essas rezas são também chamadas de breves rezas. 
O Breve pode ter se originado de breviário, que é um livro de rezas do clero católico:

O breviário representa uma compilação medieval de vários livros: o antiphonary ou livro de versos curtos (antífonas), psalter ou livro de salmos, lecionário ou livro de lições, martyrology ou o livro dos mártires, e hymnary ou livro de hinos. Foi instituido nos séculos XI e XII para a oração diária das ordens mendicantes, cujos membros não poderiam carregar uma 'biblioteca' em suas viagens. O breviário contribuiu para a privatização e a clericalização de orações diárias da Igreja. (The Harpercollins, 1995, p. 196)

Compreendo que o Breve da vovó Alayde não tenha relação com breviário, pois seu uso é eventual, na hora do parto. O breviário segue a concepção de livro em sua materialidade, é manuseado e lido diariamente, utilizado pelo clero católico.

O Breve que a seguir analisarei parece ser um misto de Breve das religiões populares e do breves rezas deixado nos altares das igrejas católicas, embora confeccionado para ser utilizado pessoalmente por mulheres no momento específico do parto.

Margareth Mead (1980), em sua obra Cultura e Compromisso, discute a natureza da cultura e o papel das diferentes gerações na sua transmissão frente aos contextos do final do século 20. Ela inicia a obra com uma dedicatória inspiradora "para a mãe de meu pai e para a filha de minha filha" (Mead, 1980, s.p.). Esta dedicatória sugere uma genealogia, aponta para vínculos com a tradição e com a inovação. Anuncia o encadeamento entre as gerações passadas, a atual e a mais jovem, a que está nascendo e a promessa de futuro que ela representa. Sinceramente, quase que eu li Para a mãe de minha mãe e para a filha de minha filha - isso não é uma citação mas uma leitura modificada que faço de $\mathrm{M}$. Mead. E por que esta leitura equivocada do realmente escrito? Pelo fato de que a respeito da mãe de meu pai eu quase não tenho objetos guardados, foram-se quase todos os suportes de memória, mas eu sei de muitas histórias a respeito da mãe de minha mãe. São histórias que estão vinculadas a objetos e não apenas a narrativas orais ou a documentos escritos ou fotografias.

Uma delas vou narrar aqui. Quando estava grávida de meu filho mais velho, num dia de janeiro, minha mãe me deu um presente dizendo: - Este é um Breve para te proteger na hora do parto. Era da mamãe e passou por todas as mulheres da família.

Em primeiro lugar destaca-se a atitude de minha mãe e sua valorização pelo que foi de minha avó. A avó, neste caso, é o referente, indica uma origem, uma descendência, um pertencimento estabilizador:

um dos elos fundamentais na corrente das narrativas de genealogias femininas é a figura da avó. Se verificarmos a simbologia da avó no imaginário literário, do mais antigo ao mais contemporâneo, deparamo-nos com a matriarca anciã, protetora, detentora de sabedoria e responsável por (re)passar para os netos a tradição e a experiência das mulheres da família. Ainda neste imaginário, a avó constitui-se figura marcante, mediadora de conflitos, portadora de legado memorial, responsável pela extensão das linhas de ancestralidade, uma ponte de ligação com uma identidade ou passado cultural. (Bezerra e Figueiredo, 2009, p. 3) 
Ao pronunciar o trecho que destaquei de Mead (1980, s.p.), na forma de minha leitura - "para a mãe de minha mãe e para a filha de minha filha" - há um grande destaque ao papel da avó, sem que este nome seja citado. É uma frase intergeracional que destaca a avó ao pronunciar "para a mãe de minha mãe", mas também sugere a avó que é ou será, aquela que lê/escreve a frase - "para a filha de minha filha".

$\mathrm{O}$ ato de oferecer o Breve não ocorreu em meio a uma entrega solene, festiva, nem o objeto estava embrulhado em papel, mas foi entregue muito simplesmente, numa conversa entre mulheres.

Que Breve é este? É um pedaço de linho beije pequeno, medindo dez por oito centímetros, com uma fita azul clara formando uma alça na parte superior e enviesado. No centro deste pedaço de pano um nome bordado - Alayde - o nome de minha avó materna. Ao tato percebia-se que havia um papel, mais parecia uma cartolina dentro.

Passando a ser meu, em minha mão, virei, olhei de um lado e de outro. Havia um toque de misterioso no objeto, bem como certo traço de pertencimento a alguém. Na parte inferior ele tinha marcas que deixavam mais nítidas as fibras do tecido, linho. Não era um objeto que tinha passado incólume por suas donas.

Era o suor ali absorvido? Ou era sangue? Quem sabe suor e sangue? Este pedaço de pano havia se colado na pele de minha avó e de outras mulheres da família? Minhas tias, quem sabe? Eram visíveis as marcas das dores de parto que este objeto de mulheres portava. Só estas marcas já traziam um exemplo, eram uma forma de ensino, uma impressão de dádiva. Como se dissessem: aqui tem força, energia de vida e de maternidade. Quase como: Não és a única, muitas mulheres de tua família já pariram, viveram e gemeram as dores do parto, deram seus filhos à luz. Ou ainda aquele Breve transmitia: o parto é suor, força e esforço, dele ficam marcas nos corpos, nas mentes e nas coisas. Aquele objeto dizia também: na hora do parto precisas de proteção, ou há muitas possibilidades e nem tudo pode dar certo. Aquele pequeno pedaço de pano que era para dar segurança e proteger dos perigos causava-me desconforto. Com ele a dúvida do parto, mas também a confiança da proteção.

$\mathrm{Na}$ ocasião nem dei tanta importância para o objeto que minha mãe me presenteava. Afinal o parto que se aproximava iria ocorrer num momento histórico em que a tecnologia e a ciência cercavam, amparavam e davam mais tranqüilidade a este momento de esperança, ansiedade e alegria. Afinal, antes do nascimento, nas consultas do pré-natal com os avanços da tecnologia, se podia ouvir os batimentos do coração do bebê, havia a ecografia para se ver em tempo real o feto em movimento e, portanto, havia medos, mas também clareza da situação e dos possíveis desdobramentos. Assim, o objeto não atuou em mim como muito possivelmente nas demais mulheres da família.

Os partos agora não eram mais realizados em casa, por parteiras. Não era preciso um Breve, pois os partos se realizavam em hospitais com recursos da ciência médica e da tecnologia da saúde a serem acionados em alguma emergência. Não mais o Breve e tudo o que ele invoca - socorro na hora do parto, tuas ascendentes já viveram esta experiência e a enfrentaram -, mas a ciência médica prevalece.

Pois bem, minha mãe me entregou o pano de sua mãe em meio a afetos e agradecimentos, mas logo outras conversas se atravessaram. Aquele objeto de memória foi guardado numa gaveta, sem que fosse usado para a finalidade que me foi recomendada, nem no primeiro e nem nos demais partos pelos quais passei. 
Há alguns anos atrás, em aula de História da Educação, ao discutir com um estudante que pesquisava culturas populares, o assunto de rezas escritas em papel e levadas por homens e mulheres como proteção por um certo grupo étnico do Rio Grande do Sul me fez relembrar o Breve que as mulheres de minha família usavam na hora do parto. Ele dizia que era um costume dos evangélicos pomeranos, ao que eu acrescentei: também entre católicas.

Foi aí que abri o saquinho de tecido que pertenceu a minha avó. Quantas surpresas! "Qualquer mulher que tiver esta oração na ocasião do parto mesmo que corra perigo se salvará." Orações em Latim e em Português estavam escritas naquelas três folhas de papel. Um papel fino, transparente, escrito dos dois lados. Havia também algumas figuras: uma imagem de Nossa Senhora das Dores, outra de Cristo crucificado e outra representando o nascimento de Jesus. Eram imagens recortadas de revistas e talvez uma delas fosse um santinho. Estavam recortadas sem muita precisão, sem cuidado com o corte reto e o ângulo perfeito. Tudo isto dobrado e amarrado com uma fita azul clara, cujas medidas estavam descritas dentro do material, assim como a maneira de fazer a amarração "amarra-se a fita em cruz. A medida é de Nossa Senhora das Dores que foi de minha mãe". Lembro novamente a dedicatória de Margareth Mead, com o viés que lhe atribuí: para a mãe de minha mãe e para a filha de minha filha. Na última página, para encerrar o conteúdo, uma data 27-9-9, seguido de "Cópia de 1 breve feito há mais de 100 anos."

Vale lembrar que entre pomeranos do Sul do Brasil foram encontradas Carta ao $c e ́ u^{2}$, semelhantes à que descrevo neste texto, mas usadas por adultos, homens e mulheres, em situações perigosas e de viagens.

Em que esta história tão particular que estou contando se relaciona com as discussões teóricas que deram início a este artigo? O objetivo não é discutir o conteúdo escrito no objeto de mulheres, a marca de formação, herança e superstição envolvida, embora estas questões não possam ser tratadas em separado do próprio suporte e seu conteúdo, mas acentuo a característica de passar de geração em geração e o objetivo de estar presente no momento do parto por diversas gerações.

Este relato destaca o parto como uma vivência particular do mundo feminino e demonstra uma estratégia intergeracional que coloca em diálogo mulheres de uma mesma família, mas de gerações diferentes. Ademais, este relato é transpassado por questões de tradição. Porque este pedaço de pano foi preservado ao longo das muitas mudanças, mortes e desfazimentos de casas, se há tantos objetos que marcam as memórias da família e que poderiam ter sido guardados? Afinal, é apenas tecido sujo e velho. Este objeto de mulheres foi conservado para ser passado por quantas gerações de

\footnotetext{
${ }^{2}$ As Cartas para o céu, encontradas entre pomeranos do Sul do Brasil e relatadas por Carmo Thum em sua tese de doutorado, lembram o breve de vovó. Thum as descreve como panos pequenos e com cordões dobrados em forma de pacotinhos que pudessem ser levados no pescoço, no bolso ou nos seios. Um dos entrevistados de Thum relata que estas cartas para o céu a ele apresentadas no momento da entrevista tinham sido escritas pelo próprio entrevistado que as copiara das de seus pais. Tais cartas eram usadas em ocasiões de perigo, quando havia viagens longas e não se sabia o que poderia acontecer; era uma reza para se proteger. Thum destaca que estes objetos de proteção não são exclusivos da cultura pomerana, estando "presentes na cultura cigana, na cultura negra, etc; contudo se fazem presentes no mundo pomerano, em língua alemã e portuguesa, sendo que as pessoas que as usam acreditam serem de sua cultura e terem o poder de proteção imaginado" (Thum, 2009, p. 61). As Cartas para o céu, em alguns casos, eram guardadas em pequenas sacolas de pano de algodão de forma a evitar que se destruíssem (Thum, 2009). 
mulheres da família? Ele foi guardado por seus poderes de proteção? Todas as mulheres que o guardaram acreditavam em sua proteção?

Certamente os partos são marcas impossíveis de serem esquecidas. Este Breve da vovó Alayde é uma lembrança, mas pode também ser considerado um material que carrega ensino e saberes? Ele traz mensagens de fé, confiança, de força nos momentos difíceis. Este objeto é portador de uma perspectiva formativa - tenha fé, leva contigo na hora do parto que é uma experiência tua, mas, lembra, outras mulheres da família já passaram por ele. Traz também uma perspectiva de linhagem, de origens, articulação no tempo e com outras mulheres da família. Como afirmei anteriormente, por meio dele as gerações dialogam e se apóiam entre si.

Este Breve não chega a ser uma memória de família a ser dada como proteção a todos, compartilhada entre homens e mulheres, mas é a memória marcadamente feminina, passada entre gerações de mulheres. Mas mesmo nas memórias de família? 0 que seria se minha avó tivesse gerado apenas filhos homens? Para quem seria ofertado o objeto de mulheres? Na hipótese de eu conservar este Breve da vovó Alayde e passá-lo para minha filha e esta passar para minha neta, que tradição estaria sendo preservada? A crença na salvação? Mas a salvação na forma de um papel escrito, guardado dobrado? Fé? Mas fé se entrega de geração em geração?

Este Breve da vovó Alayde passa a ser apenas uma marca das mulheres e da presença delas na família, com significação exclusiva para parturientes ou traz um significado para além dos partos? Poderá ele deixar de ser uma oração mágica para a hora do parto e passar a ser um Breve para a vida em todas as situações? Uma marca da força das mulheres? Um pano que grita: ânimo na vida! Porque pelo menos as mulheres que o tiveram depois de minha avó não abriram o Breve e não leram o que havia dentro? Ler o que estava escrito significa quebrar a proteção almejada? Abrir, ler o conteúdo significa insubmissão, infidelidade à tradição?

No caso do Breve da vovó Alayde foi escrito por sua irmã mais velha; sua mãe morreu cedo. Mas um Breve tradicionalmente deveria ser escrito pela mãe da parturiente ou por uma mulher de sua família que estivesse mais próxima dela e que já tivesse passado pela experiência do parto?

Este exemplo é instigante para pensar a tradição em nossas vidas e na História da Educação. Afinal que mulheres escrevem o que? Porque escrever e reescrever um Breve? Quais as fontes de família que poderão nos informar como as mulheres aprendem a serem mulheres? Quem escreve a história a respeito de como as mulheres ajudam outras mulheres no cotidiano de suas vidas? Como as gerações comunicam seus saberes a respeito de suas experiências? Como e o que as mães ensinam a suas filhas e às amigas de suas filhas? Como e o que mulheres que são irmãs se ensinam mutuamente?

Este é um tema presente na Historia da Educação? A Historia da Educação considera a genealogia feminina como fonte e instigação para a pesquisa? A tradição da História da Educação é predominantemente voltada para a história da escola, dos saberes escolares, dos sistemas e políticas educacionais. Mas as superstições, as práticas religiosas e os costumes familiares não chegam até as salas de aula?

A dedicatória "para a mãe de meu pai [ou, na leitura que faço, para a mãe de minha mãe] e para a filha de minha filha" do livro de Margareth Mead (1980, s.p.), situa-se nesta idéia de tradição e de genealogia feminina? O Breve de minha avó, escrito por sua irmã 
mais velha, passado para minhas tias e minha mãe, sem que elas soubessem o que estava escrito nele, dado para mim, a segunda geração, presentifica também uma tradição. Mas qual? A de que é importante mulheres de uma mesma família manterem práticas de ajuda mútua? De que mulheres de gerações anteriores são referências em nossas famílias e se preocupam em transmitir práticas que consideram importantes para as gerações posteriores? Ou a tradição vinculada a uma superstição de que a proteção contida no Breve estava preservada e amarrada dentro daquele pedaço de pano.

Sim, no material que chamei de objeto de mulheres e na reflexão que fiz, estão contidas tradição, inovação, apropriação, recontextualização. Por que o nome de minha avó e não o nome de cada parturiente? Para marcar a ancestralidade?

O Breve da vovó Alayde, aberto em sua interioridade informa, em parte, o que faziam as avós, bisavós e mães para se prepararem para o parto. Sugere tradições, hábitos e uma estratégia de manutenção de uma linhagem. É um pequeno pedaço de tecido que permite recuperar um fragmento das práticas femininas do final do século $19 \mathrm{e}$ início do século 20, permite recuperar a memória e contar a história de mulheres e a forma destas se relacionarem entre si e com as diferentes gerações.

O pequeno pedaço de tecido e o conteúdo que esconde, representa uma forma de diálogo silencioso entre gerações relacionado a uma ocorrência importante na vida das mulheres: o dar a luz, o parto. Ele indica uma estratégia de interlocução, embora silenciosa, entre mulheres de diferentes gerações de uma mesma família. Ele estabelece laços, apoios, segredos. Pode-se conjecturar que falar a respeito do parto em si, das dores, das mudanças no corpo e seu impacto nas relações familiares e consigo mesma fosse difícil, doloroso. Cabe ao Breve carregar experiências impronunciáveis?! Para as gerações anteriores o pedaço de pano com papéis dentro poderia, talvez, substituir, representar, acompanhar ou anteceder uma conversa íntima? São indagações que permanecem como hipóteses e questões não respondidas.

Este pedaço de tecido, com suas folhas de papel dobradas e amarradas, constitui-se num laço entre gerações, carrega um modelo para as gerações mais jovens, uma proposta de formação - quando tua filha estiver na hora do parto, esteja presente, dê-lhe este presente. Ele atua como um elo de gerações, constrói afinidades e oferece um conhecimento do passado o qual atua como referência, memória e localização histórica e geracional.

\section{Referências}

ALMEIDA, Lélia. Genealogias femininas em $O$ penhoar chinês de Rachel Jardim. Especulo, Revista de Estúdios Literários, Madrid, 2003, p. 1-22. Disponível em $<$ http://www.ucm.es/info/especulo/numero24/genealog.html>. Acesso em 20 jan. 2013.

BEZERRA, Anna Giovanna Rocha; FIGUEIREDO, Ediliane Lopes Leite. Hiato entre gerações: a cândida neta e a desalmada avó de Gabriel García Márquez. COLÓQUIO INTERNACIONAL CIDADANIA CULTURAL: DIÁLOGOS DE GERAÇÕES, 4, 2009. Anais ... Campina Grande: UFCG, 2009, p. 1-8.

BORNHEIM, Gerd. O conceito de tradição. BORNHEIM, Gerd et al Cultura brasileira: tradição e contradição. Rio de Janeiro: Zahar, 1997, p. 13-30.

BURKE, Peter. Abertura: a nova história, seu passado e seu futuro. In: BURKE, Peter, (org.). A escrita da história: novas perspectivas. São Paulo: Unesp, 1992, p. 7-38. 
BURKE, Peter. Cultura, tradição, educação. In: GATTI JÚNIOR, Décio; PINTASSILGO, Joaquim (orgs.). Percursos e desafios da pesquisa e do ensino de história da educação. Uberlândia: Edufu, 2007, p.13-22.

BURKE, Peter. Hibridismo cultural. São Leopoldo: Unisinos, 2003.

HOBSBAWN, Eric; RANGER, Terence (org.). A invenção das tradições. Rio de Janeiro: Paz e Terra, 1997.

THE HARPER COLLINS DICTIONARY OF RELIGION. New York, 1995.

IRIGARAY, Luce. A questão do outro. Labrys, Estudos feministas, n. 1-2, 2012, p. 1-12. Disponível em <http://www.unb.br/ih/his/gefem/labrys1 2/irigaray1.html>. Acesso em 3 jan., 2012.

LIMA, Licinio. A escola como organização educativa. São Paulo: Cortez, 2001.

MEAD, Margaret. Cultura y compromiso: estúdio sobre la ruptura geracional. Barcelona: Gedisa, 1980.

THUM, Carmo. Educação, história e memória: silêncios e reinvenções pomeranas na Serra dos Tapes. São Leopoldo: Unisinos, 2009. 384f. Tese (doutorado em Educação). Programa de Pós-Graduação em Educação, Universidade do Vale do Rio dos Sinos.

SUÁREZ, Daniel H. I'nvestigación educativa, memória docente y documentación narrativa de experiencias pedagógicas. In: FERREIRA, Márcia Ondina; FISCHER, Beatriz Daudt; PERES, Lúcia Maria (org.). Memórias docentes: abordagens teórico-metodológicas e experiências de investigação. São Leopoldo: Oikos; Brasília: Liberlivro, 2009, p. 15-34.

VIÑAO, Antonio, Sistemas educativos, culturas escolares y reformas. Madrid: Morata, 2002.

WEIDUSCHADT, Patrícia; FISCHER, Beatriz Daudt. História oral e memória: aportes teórico-metodológicos na investigação de trajetórias docentes. In: FERREIRA, Márcia Ondina; FISCHER, Beatriz Daudt; PERES, Lúcia Maria (org.). Memórias docentes: abordagens teórico-metodológicas e experiências de investigação. São Leopoldo: Oikos; Brasília: Liberlivro, 2009, p. 66-82.

FLÁVIA OBINO CORRÊA WERLE é doutor em Educação pela Pontifícia Universidade Católica do Rio Grande do Sul, pesquisador CNPq, professora e pesquisadora da Universidade do Vale do Rio dos Sinos - Unisinos, orientadora de doutorado, pesquisadora da área de historia da educação e políticas educacionais. Endereço: Avenida Unisinos 950 - 93022-000 - São Leopoldo - RS - Brasil. E-mail: flaviaw@unisinos.br.

Recebido em 26 de setembro de 2013. Aceito em 7 de fevereiro de 2014. 